\title{
É PRECISO QUESTIONAR OS USOS DE GÊNERO NAS TRAMAS DO CURSO GPP-GeR?
}

\author{
Raimunda Nonata da Silva Machado(*) \\ Francis Musa Boakari ${ }^{(* *)}$
}

\section{Resumo}

Estudo sobre a categoria gênero no Curso Gestão de Políticas Públicas em Gênero e Raça (GPP-GeR), oferecido pela Universidade Federal do Maranhão (UFMA), no contexto atual de políticas de formação na área das diversidades. Analisa os usos que se faz da noção de gênero, indagando se há ou não ruptura com a visão substancialista desse conceito.

Palavras-chave: Gênero. GPP-GeR. Diversidades. Epistemologia

\begin{abstract}
This study is about gender as a category in the Public Policy Management Course on Gender and Race (GPP-GeR), offered by the Federal University of Maranhão (UFMA), in the current context of training in the area of diversity. Analyzes the uses of the concept of gender, asking whether or not there is a break with the essentialist understanding of this concept.
\end{abstract}

Keywords: Gender. GPP-GeR. Diversities. Epistemology

\section{Introdução}

O discurso de gênero oferece ou não possibilidade de desconstrução da visão substancialista ou, apenas reconhece identidades diferentes para justificar a posição social dos sujeitos? Em cursos de formação de profissionais da educação o uso da noção de gênero é capaz de fazer ruptura com a visão normativa? De que modo isto seria possível?

Essas questões merecem ser privilegiadas porque estiveram, por muito tempo, ausentes das pesquisas que envolvem a formação de profissionais na educação superior. Para

\footnotetext{
(*)Professora do Curso de Licenciatura Interdisciplinar em Ciências Naturais/Biologia da Universidade Federal do Maranhão (UFMA) e Doutoranda do Programa de Pós-Graduação em Educação da Universidade Federal do Piauí (UFPI), Teresina, PI, Brasil. Emai: rainsmachado@gmail.com

${ }^{(* *)}$ Professor Pós-Doutor do Centro de Ciência da Educação e do Programa de Pós-Graduação em Educação (Mestrado e Doutorado), ambos da Universidade Federal do Piauí (UFPI), Teresina, PI, Brasil. Email: musabuakei@yahoo.com
} 
André (2010, p. 50), nos anos 2000 surgem pesquisas sobre os cursos superiores de magistério e os "estudos que tratam de questões de gênero, etnia e das competências na formação do professor foram praticamente silenciados nos anos recentes, contrariando as suas expectativas em 2000, que os considerava temas emergentes" ${ }^{1}$.

O foco na emergência de temas como: a formação de professores de cursos superiores; o uso de tecnologias educacionais e a educação a distância na formação de professores (ANDRÉ, 2010), somados ao desenvolvimento de políticas públicas na área da diversidade nos anos 2000, vêm influenciando na inclusão das preocupações com as questões de gênero na formação de profissionais da educação.

Ora, as políticas públicas, também atravessam o contexto da sociedade na era das Tecnologias da Informação e Comunicação (TICs), exigindo a participação das Universidades nesse processo, enquanto espaço de formação dos sujeitos; de produção e disseminação de conhecimentos que colabora com a estruturação da vida social, por meio do desenvolvimento de políticas educacionais.

Dentre as diversas políticas que influenciam as ações na universidade, destacamos as atuais políticas de conhecimento na área da diversidade cultural que são desenvolvidas na modalidade de educação a distância, fazendo uso integrado de TICs, no âmbito do Sistema Universidade Aberta do Brasil (Sistema UAB), tendo em vista a própria estruturação da "sociedade informacional” (CASTELLS, 2011).

Nessa perspectiva, o Sistema UAB foi criado em 2005 e instituído pelo Decreto 5.800, de 8 de junho de 2006, para "o desenvolvimento da modalidade de educação a distância, com a finalidade de expandir e interiorizar a oferta de cursos e programas de educação superior no País"2. Para Dias; Leite (2010, p. 27), o sistema UAB "não é uma nova

\footnotetext{
${ }^{1}$ ANDRÉ, Marli E. D. A. A produção acadêmica sobre formação de professores: um estudo comparativo das dissertações e teses defendidas nos anos 1990 e 2000. Formação Docente - Revista Brasileira de Pesquisa sobre Formação Docente, Belo Horizonte, v. 1, n. 1, ago./dez. 2009. P. 41-56. Disponível em: $<$ http://formacaodocente.autenticaeditora.com.br. $>$. Acesso em: 12 jun. 2013.

${ }^{2}$ Mais informações no site: http://uab.capes.gov.br/.
} 
instituição de ensino e se articula com os governos estaduais, municipais e instituições públicas de Ensino Superior, com ação prioritária na formação inicial e continuada de professores para a educação básica."3

O desenvolvimento dos processos de ensino e aprendizagem na modalidade de educação a distância vem se aprimorando e expandindo no Brasil, embora com bastante assimetria regional, conforme demonstra o Censo EAD.Br (2014, p. 24)

\begin{abstract}
$\mathrm{Na}$ Região Norte há uma dependência marcante dos cursos de EAD realizados na esfera pública federal, que são $84 \%$ do total. Os outros são cursos de instituições estaduais ou do Sistema "S" (Senai, Senac, Senar e outros). Não há nessa região projetos privados relevantes que tenham sido detectados por esta pesquisa.

É um perfil que começa a se alterar e se tornar mais híbrido na Região Nordeste, onde $49 \%$ dos cursos são provenientes de instituições privadas, mas que se torna abissalmente diferente na Região Sudeste, onde nada menos que $82 \%$ dos cursos estão na esfera privada (aparentemente essa região, com $48,36 \%$ dos cursos, foi a que levou a média nacional para um resultado bem próximo do seu perfil), e na Região Sul, com 91\% dos cursos na esfera privada. ${ }^{4}$ (Grifos meus)
\end{abstract}

Esse perfil de cursos EAD, por distribuição geográfica, mostra a complexidade de seu uso para "suprir a grande demanda por educação no país em ambientes institucionais distintos" (CENSO EAD.BR, 2014, p. 24) com conteúdos de ensino e aprendizagem plurais. É nesse contexto de políticas educacionais que o Curso GPP-Ger se insere, focalizando a educação para a diversidade, mediante a oferta de um conjunto de cursos realizados na esfera pública federal, por meio do Sistema UAB, na modalidade de educação a distância. Para Heilborn; Araújo; Barreto (2010, p. 11)

[...] Esta modalidade de ensino busca associar os avanços tecnológicos e a eficiência de recursos materiais com a qualidade de recursos humanos representados por especialistas acadêmicos e gestores na análise e proposição de questões sociais que caracterizam a sociedade brasileira. ${ }^{5}$

Desse modo, indagamos qual o propósito deste curso? Que noção de gênero é discutida nesse curso e quais poderiam ser suas implicações na formação docente? Estas preocupações fazem parte dos estudos que estão sendo desenvolvidos por nós na

${ }^{3}$ DIAS, Rosilânia A.; LEITE, Lígia S. Educação a Distância: da legislação ao pedagógico, Petrópolis, RJ: Vozes, 2010.

${ }^{4}$ CENSO EAD.BR: relatório analítico da aprendizagem a distância no Brasil 2013. Trad. Maria Thereza Moss de Abreu. Curitiba: Ibpex, 2014.

${ }^{5}$ HEILBORN, Maria Luiza; ARAÚJO, Leila; BARRETO, Andreia. (Org.). Gestão de Política Públicas em Gênero e Raça | GPP-GeR: módulo II. Rio de Janeiro: CEPESC; Brasília: SPM/MEC, 2010. 
pesquisa de doutorado intitulada: "Gênero e Raça na Educação à Distância: outras epistemologias na prática educativa de formação docente?”, sendo que, neste artigo, o recorte teórico-metodológico da pesquisa qualitativa privilegia procedimentos da etnografia virtual (HINE apud BRAGA, 2012), dialogando com autores/as que discutem, preferencialmente, educação a distância, epistemologias e concepções de gênero, tais como: Aboud (2008), Boakari (2010), Butler (2012), Castells (2011), Dias; Leite (2010), Heilborn; Araújo; Barreto (2010), Lauretis (1994), Louro (2000), Moore; Kearsley (2010), Morin (2007), Santos (2008; 2010), Scott (1995; 1999), dentre outros.

O recorte metodológico da etnografia virtual (abordagem interdisciplinar aplicada aos ambientes online) vem emergindo da própria experiência de pesquisa, consoante com o entendimento de Morin (2007, p. 20) de que "o método não precede a experiência, o método emerge durante a experiência e se apresenta ao final, talvez para uma nova viagem." Trata-se, portanto, de uma tentativa de reflexão sobre as possibilidades epistemológicas incentivadas no âmbito do Sistema UAB desenvolvidas na UFMA, dentre outras instituições de educação superior, e que podem ser capazes de estimular intervenções que implicam em rupturas com as formas conservadoras e discriminatórias de conceber a noção de gênero.

Dessa forma, discutiremos, a seguir, a organização e funcionamento do Curso GPP-GeR, bem como os usos da noção de gênero pelos participantes durante o processo de formação.

\section{Gênero nas políticas públicas com foco na formação: o Curso GPP-GeR}

A produção dos sujeitos e as relações entre os sujeitos sempre foi uma preocupação das políticas públicas, notadamente, no âmbito educacional, tendo os sistemas escolares como "um espaço de normalização, disciplinamento e ajustamento heteronormativo de corpos, mentes, identidades e sexualidades"” (HENRIQUES et al, 2007, p. 11).

\footnotetext{
${ }^{6}$ MORIN, Edgar [et all]. Educar na era planetária: o pensamento complexo como método de aprendizagem no erro e na incerteza humana. São Paulo: Cortez, Brasília, DF: UNESCO, 2007.

${ }^{7}$ HENRIQUES, Ricardo et al. Gênero e Diversidade Sexual na Escola: reconhecer diferenças e superar preconceitos. Brasília: SECAD/MEC, 2007
} 
A partir dos anos 1970, os movimentos feministas brasileiros desenvolveram discussões e ações no interior das escolas, denunciando essa tradição de educação heteronormativa como produtora de desigualdades sociais para contribuir com formulações pedagógicas feministas ou práticas educativas não-sexistas. Para Louro (2004, p. 112-113):

\begin{abstract}
A partir da constatação de que a educação formal - na sua concepção, em suas políticas e suas práticas - havia sido e continua a ser definida e governada pelos homens, estudiosas feministas procuraram produzir um paradigma educacional que se contrapussesse aos paradigmas vigentes.

[...] um novo modelo pedagógico construído para subverter a posição desigual e subordinada das mulheres no espaço escolar, a pedagogia feminista vai propor um conjunto de estratégias, procedimentos e disposições que devem romper com as relações hierárquicas presentes nas salas de aula tradicionais. $^{8}$
\end{abstract}

A principal referência oficial que temos para o tratamento das temáticas relacionadas à questão de gênero no campo educacional, ainda são os cadernos de Temas Transversais (especialmente os que tratam da temática orientação sexual) dos Parâmetros Curriculares Nacionais (PCN) para o Ensino Fundamental, publicados pelo MEC em 1998 no contexto das reformas curriculares instauradas nos anos 1990 e, nesse sentido, as políticas curriculares ou de conhecimento são alvo de atenção, seja tentando "regular e orientar crianças e jovens dentro dos padrões que consideram moralmente sãos", seja acentuando "o caráter social e cultural do feminino e do masculino, tentando ampliar o acento marcadamente biológico com que as questões costumam ser tratadas9" (LOURO, 2004, p. 130-131).

Para Henriques (2007), as iniciativas governamentais, em defesa dos direitos humanos das mulheres, se consolidou com o Plano Nacional de Políticas para as Mulheres (PNPM), aprovado pelo Decreto $\mathrm{n}^{0} 5.390$, de 8 de março de 2005 que, no âmbito da política educacional brasileira, buscou enfrentar a problemática de gênero e diversidade de orientação sexual, por meio de três eixos:

Eixo 1: Planejamento, Gestão e Avaliação: tem como foco a transversalização das agendas de gênero e diversidade sexual com desdobramento para as seguintes demandas: intersetorialidade, transversalidade e focalização e inovação, na tentativa de

\footnotetext{
8 LOURO, Guacira L. Gênero, sexualidade e educação: uma perspectiva pós-estruturalista. Petrópolis: Vozes, 2004.

${ }^{9}$ Ibdem, p. 130-131
} 
atender as agendas referentes às de gênero e orientação sexual, bem como raça, etnia, diversidade religiosa, cultural, geracional, entre outras.

Eixo 2: Acesso e Permanência: visa ampliar o ingresso e a permanência, com sucesso, de mulheres e da população LGBT em todos os níveis e modalidades de ensino, atreladas à melhoria da qualidade de atendimento e valorização de profissionais de educação, incluindo políticas de ação afirmativa voltadas a grupos específicos, como transgêneros, transexuais, mulheres pobres acima de 40 anos, quilombolas, indígenas, mulheres presidiárias ou jovens internas em cumprimento de medidas socioeducativas, entre outras.

Eixo 3: Formação de profissionais da educação: é considerada de fundamental importância para êxito dos eixos anteriores, tendo como foco as ações de educação para a igualdade de gênero e o respeito à diversidade de orientação sexual, fazendo um amplo debate sobre a centralidade dos princípios dos direitos humanos e do reconhecimento das diversidades.

A principal intencionalidade desta política é a busca da equidade, do reconhecimento e valorização das diferenças, atendendo demandas históricas dos movimentos sociais, dos protestos públicos de grupos de "intelectuais, estudantes, negros, mulheres, jovens, enfim, diferentes grupos que, de muitos modos, expressam sua inconformidade e desencanto em relação aos tradicionais arranjos sociais e políticos ${ }^{10 "}$ (LOURO, 2004, p.16).

É nesse terceiro eixo que iremos concentrar nossas discussões, a partir da análise de um curso criado com a intenção de contribuir nessa produção de novos sentidos e significados acerca, dentre outros, das relações de gênero, ou seja, das relações sociais em que os gêneros são construídos, do debate que mostra como essas relações são determinadas de modo naturalizado, seja por diferenças biológicas ou culturais, desconsiderando a história, as condições de acesso dos sujeitos aos direitos sociais.

O curso de Gestão de Políticas Públicas em Gênero e Raça (GPP-GeR) é resultado do Projeto Gênero e Diversidade na Escola, desenvolvido por universidades brasileiras desde 2006. Este curso foi instituído, a partir de 2009, com a criação da Rede de Educação para a Diversidade (Rede), pelo Ministério da Educação (MEC), em

${ }^{10}$ Ibdem, p. 16 
parceria com a Secretaria de Políticas para as Mulheres (SPM/PR); a Secretaria de Políticas de Promoção da Igualdade Racial (SEPPIR/PR); a Secretaria de Educação Continuada, Alfabetização e Diversidade (SECAD/MEC) ${ }^{11}$; o Ministério do Planejamento, o Instituto de Pesquisas Aplicadas (IPEA), o Fundo das Nações Unidas para a Mulher (UNIFEM) e o Centro Latino Americano em Sexualidade e Direitos Humanos (CLAM) criado no âmbito do Programa em Gênero, Sexualidade e Saúde do Instituto de Medicina Social da Universidade do Estado do Rio de Janeiro (UERJ). (BRASIL, 2012)

A implementação da Rede se deu no âmbito do Sistema UAB, articulando sistemas de ensino das redes públicas estaduais e municipais de educação básica e universidades brasileiras para atender professores de educação básica e outros profissionais da educação das redes públicas de ensino; pesquisadores nas áreas da diversidade e gestores dos sistemas de ensino federal, estaduais e municipais, visando fomentar a formação inicial e continuada a distância para a "produção de conteúdos e o desenvolvimento de metodologias educacionais que integram as temáticas da diversidade" (BRASIL, 2012, p. 6), tais como:

\begin{abstract}
Educação para a Diversidade, Educação de Jovens e Adultos na Diversidade, Educação do Campo, Educação para as Relações Étnico-Raciais, Educação Ambiental, Educação Integral e Integrada, Gênero e Diversidade na Escola, Saúde na Escola, Educação para os Direitos Humanos, Produção de Material Didático para a Diversidade, Educação Escolar, Culturas e História dos Povos Indígenas e Mediadores de Leitura, temas da atualidade no cotidiano das práticas das redes de ensino pública da educação básica no Brasil ${ }^{12}$. (BRASIL, 2012, p. 6)
\end{abstract}

Para dar conta deste propósito, a Rede ficou responsável por:

- ampliar as oportunidades de formação de educadores e gestores educacionais da rede pública da educação básica;

- ofertar cursos nas modalidades de extensão, aperfeiçoamento e especialização;

\footnotetext{
11 A partir de 2011, A Secretaria de Educação Continuada, Alfabetização e Diversidade (SECAD-MEC) passou a denominar-se Secretaria de Educação Continuada, Alfabetização, Diversidade e Inclusão (SECADI/MEC)com foco nas áreas de alfabetização e educação de jovens e adultos, educação ambiental, educação em direitos humanos, educação especial, do campo, escolar indígena, quilombola e educação para as relações étnico-raciais.

12 BRASIL. Ministério da Educação. Manual da Rede de Educação para a Diversidade. Disponível em: $<\underline{\text { http://portal.mec.gov.br/index.php?option=com content\&view=article\&id=12322\&Itemid=561. }}$. . Acesso em: 2 mar. 2012
} 
- elaborar metodologias e conteúdos específicos;

- fomentar a adesão e o desenvolvimento de propostas das IPES nos temas e áreas da diversidade;

- fomentar e avaliar a inserção dos temas da diversidade nos programas de educação da rede pública de ensino;

- estabelecer normas para o funcionamento e certificação dos cursos ofertados $^{13}$. (BRASIL, 2012, p. 6)

De acordo com o Edital n ${ }^{\circ} 28$ SECAD/MEC de 23 de novembro de 2009, a Rede de Educação para a Diversidade (Rede) é uma "denominação representativa genérica para o conjunto de instituições públicas de ensino proponentes de cursos de formação inicial ou continuada a serem ofertados na modalidade de educação a distância", sendo este conjunto de cursos ofertados no âmbito do Sistema UAB são denominados de Programa de Formação para a Diversidade, distribuídos em duas partes para que as instituições integrantes do Sistema UAB encaminhem suas propostas conforme as diretrizes dispostas no Manual Operacional da Rede. São eles:

PARTE A: propostas para os cursos por áreas temáticas

1. Curso de Educação para a Diversidade (180h);

2. Curso de Educação de Jovens e Adultos na Diversidade (180h);

3. Curso de Educação do Campo A e B (2 cursos de 180h);

4. Curso de Educação para as Relações Étnico-Raciais (180h);

5. Curso de Educação Ambiental (180h);

6. Curso de Educação Ambiental: escolas sustentáveis e Com-Vida (90h);

7. Curso de Educação Integral e Integrada (220h);

8. Curso de Gênero e Diversidade na Escola (200h);

9. Curso de Educação em Direitos Humanos (200h);

10. Curso de Produção de Material Didático para a Diversidade (180h);

11. Curso de Educação e Saúde (180h);

12. Curso de Formação de Gestores para programas de Educação Escolar Indígena (180h);

13. Curso de Formação de Professores na temática Cultura e História dos Povos Indígenas (240h);

14. Curso de Formação para Mediadores de Leitura (90h);

15. Curso sobre o Estatuto da Criança e do Adolescente (90h);

${ }^{13}$ Ibdem, p. 6. 
16. Curso Diversidade no Ambiente Escolar (90h).

PARTE B: Propostas para os cursos de gestão de políticas públicas com foco na temática de gênero e raça - O Curso GPP-GeR

1. Curso de aperfeiçoamento e/ou extensão em Gestão de Políticas Públicas com foco na Temática de Gênero e Raça (300h);

2. Curso de Especialização em Gestão de Políticas Pública com foco na Temática de Gênero e Raça (380h)

O Curso GPP-GeR, nos chamou atenção por sua especificidade de Gestão de Políticas Públicas, no âmbito de um Programa destinado a professores, gestores e demais profissionais da educação básica, no sentido de ajudá-los "a vencerem os desafios do reconhecimento, da valorização e da inserção das temáticas da diversidade nas práticas pedagógicas e no cotidiano das salas de aula ${ }^{14 "}$ (BRASIL, 2012, p. 7). A nosso ver, este curso amplia o propósito de incorporação dos temas da diversidade na sala de aula, dando atenção aos diferentes níveis e setores da administração pública e áreas sociais como: educação, saúde, trabalho, segurança e planejamento, objetivando "formar profissionais aptos a atuar no processo de elaboração, aplicação, monitoramento e avaliação de projetos e ações de forma a assegurar a transversalidade e a intersetorialidade de gênero e raça nas políticas públicas ${ }^{15 ”}$. (BRASIL, 2012, p. 109)

A Universidade Federal do Maranhão foi uma das instituições que aderiu ao Programa de Formação para a Diversidade. Esta instituição foi credenciada no Sistema UAB, em março de 2006, visando ofertar cursos de extensão, aperfeiçoamento, graduação e pós-graduação a distância, por meio do Núcleo de Educação a Distância (NEaD), sendo que, a partir de 2009, iniciou a oferta de cursos da Rede de Educação para a Diversidade, dentre eles o Curso GPP-GeR (INTERATIVA, 2008; 2010), um curso instrumentalizador para atuação com intervenções fundamentadas em todas as fases das políticas públicas: definição da agenda; Formulação de políticas, com

\footnotetext{
${ }^{14}$ Ibdem, p. 7.

15 Ibdem, p. 109
} 
identificação de alternativas, avaliação das opções e seleção das opções; Implementação da política pública e Avaliação (HEILBORN; ARAÚJO; BARRETO, 2010a).

Na UFMA, O Curso GPP-GeR aconteceu no período de 2011 a 2013, em nível de especialização com carga horária de 390h, atendendo aos municípios de Caxias, Grajaú, Imperatriz, Codó, Santa Inês e Humberto de Campos, na modalidade de educação a distância do tipo semipresencial, fazendo uso do Ambiente Virtual de Aprendizagem Moodle (AVA Moodle) ${ }^{16}$, o qual foi estruturado no formato de tópicos para agrupar os conteúdos, já distribuídos no projeto do curso em seis módulos:

1. Políticas Públicas e Promoção da Igualdade

2. Políticas públicas e gênero

3. Políticas públicas e raça

4. Estado e sociedade

5. A transversalidade de gênero e raça na gestão pública

6. Metodologia de Projetos de Pesquisa e de Intervenção

A formação foi realizada, por meio de encontros presenciais e virtuais, fazendo uso de ferramentas que armazenaram arquivos de consulta (livros, artigos, vídeos, dentre outros) e que propiciaram a produção de atividades (textos individuais e coletivos), principalmente, por meio de recursos como: os diários, os fóruns e as tarefas, como também interações individualizadas.

Desse modo, considerando que, nesse artigo, iremos nos deter na compreensão dos usos que os participantes fazem da noção de gênero neste curso, focalizaremos, a seguir, a análise do Módulo 2: Políticas públicas e gênero, especificamente, a Unidade 1 que trata dos conceitos: gênero, sexo e sexualidade, bem como as postagens disponibilizadas nos fóruns, tendo em vista que os debates sobre os conceitos de gênero foram desenvolvidos, sobretudo, nesta ferramenta.

\footnotetext{
16 Trata-se de um ambiente fechado, por meio de contas de usuários e senhas, tal como a ferramenta da web 2.0 GoogleDocs. Este ambiente permite um maior controle da produção e autoria colaborativa e oferece a possibilidade de armazenar e compartilhar informações, as quais podem ser bem utilizadas por um grupo de pessoas que desejam compartilhar ideias em discussão, produzir artigos, relatos de experiência e memorial reflexivo, dentre outros, de forma colaborativa.
} 


\section{Usos da noção de gênero no processo de formação do Curso GPP-GeR}

A análise do conceito de gênero, estudado no curso GPP-GeR, consiste em tentar perceber se oferecem ou não possibilidades de desconstrução da concepção substancialista (BACHELARD, 1996), cuja visão, reconhece identidades diferentes, mas na tentativa de justificar a posição dos sujeitos na sociedade, mediante distribuição natural de papéis que caracterizam sujeitos objetivos e subjetivos, inferiores e superiores, normais e desviantes, dentre outros.

O pensamento substancialista, em Bachelard (1996) é uma construção da ciência clássica, na qual predomina um modo de conhecer baseado nas tradições racionalistacartesiano, empirista-baconiano e positivistas. Corresponde, também, ao que Santos (2008, p. 21) chama de "modelo global de racionalidade científica ${ }^{17 ",}$, que nega outros tipos de saberes de culturas não oficialmente europeias, bem como formas de conhecimentos que consideram do senso comum.

O gênero compreendido em termos de substância é utilizado de forma imutável, fixo e como única razão para atribuir qualidades ou adjetivações que definem identidades universais, causando obstáculo ao reconhecimento de outros modos de pensar e mudanças nas estruturas de poder estabelecido como hegemônico, normativo e racional. Empregar adjetivações que qualificam, por exemplo, as mulheres universalmente como frágeis, sensíveis, procriadoras, dentre outras, é negar, a participação dessas mulheres na produção de bens econômicos e socioculturais da sociedade, mantendo e naturalizando a distribuição de poder.

Além disso, o modo de pensar substancialista constitui obstáculo epistemológico, porque, como afirma Machado (2008, p. 56), não considera, historicamente, que os sujeitos não são unificados e que existe 
sociais, bem como definir os seres humanos em objetivos e subjetivos, inferiores e superiores ${ }^{18}$.

Esse modo de pensar relações de gênero privilegia as hierarquizações sociais, dando primazia a qualidades (adjetivações) que acentuam as diferenças como modo socializado de inferiorizar e desprestigiar as experiências de certos sujeitos, no sentido de manter relações hegemônicas de poder. Desse modo, o pensamento substancialista é, também, obstáculo às lutas e conquistas das mulheres quanto aos direitos sociais (educação, saúde, trabalho, moradia, dentre outros) tanto que Saffioti (1987, p.14), afirma que:

\begin{abstract}
O argumento de que há muito poucas mulheres dentre os grandes cientistas, até grandes cozinheiros, tenta provar que também em termos de inteligência a mulher é inferior ao homem. Os portadores e divulgadores desta ideologia esquecem-se de medir as oportunidades que foram oferecidas, ou melhor, negadas às mulheres. Ao atribuir a elas a responsabilidade praticamente exclusiva pela prole e pela casa, já se lhes está, automaticamente, reduzindo as probabilidades de desenvolvimento de outras potencialidades de que são portadoras ${ }^{19}$.
\end{abstract}

Então, investigar quais foram as noções de gênero produzidas no Curso GPPGeR, torna-se relevante para avaliarmos a visão que os participantes têm acerca das relações de gênero, já que o propósito desta formação consiste em elaborar e desenvolver políticas de gênero em interseção com as questões raciais. Disso tudo resulta nossa preocupação com a análise dos usos do conceito de gênero, averiguando possibilidades de ruptura ou não com formas substancialistas de conhecer o mundo social, já que, esta postura tem implicação na realização de projetos sociais das diversas áreas envolvidas neste processo educativo, de acordo com os movimentos que existem entre concepções epistemológicas diferentes e que são capazes de gerar mudanças nas relações sociais, considerando a emergência de novos pensamentos. Esse processo pode ser melhor compreendido por Kuhn (1998, p. 95) quando diz que:

A emergência de novas teorias é geralmente precedida por um período de insegurança profissional pronunciada, pois exige a destruição em larga escala de paradigmas e grandes alterações nos problemas e técnicas da ciência normal. Como seria de esperar, essa insegurança e gerada pelo fracasso

\footnotetext{
18 MACHADO, Raimunda N. da Silva. Mulher negra: ressignificando o discurso no espaço escolar. Dissertação (Mestrado em Ciências Sociais). Programa de Pós Graduação em Ciências Sociais/ Universidade Federal do Maranhão. São Luís: UFMA, 2008.
}

${ }^{19}$ SAFFIOTI, Heleieth I. B. O poder do macho. São Paulo: Moderna, 1987. 
constante dos quebra-cabeças da ciência normal em produzir os resultados esperados. O fracasso das regras existentes e o prelúdio para uma busca de novas regras ${ }^{20}$.

Mas, que epistemologias estão sendo utilizadas como fundamento para o desenvolvimento da pedagogia de gênero no GPP-GeR? Isto leva a problematização do GPP-GeR, como um sistema de conhecimentos (diálogo, encontros de experiências, epistemologias...) das questões de gênero em que suas interpretações são resultados de diferentes tecnologias sociais como: o próprio GPP-GeR, mais também, a televisão, o cinema, as práticas da vida cotidiana (LAURETIS, 1994), tanto que Motta (2002, p.14) adverte: "Todo cuidado é preciso com teorias e conceitos, pois são usados por certos grupos para manter a si mesmos e seus projetos ${ }^{21}$ ”.

Nessa relação com a teoria, se insere a própria organização do ensino universitário baseada por um modelo disciplinar em que predomina o conhecimento científico com características de homogeneidade, universalidade, hierarquização e objetividades, sendo que a emergência ou a presença de outros conhecimentos pode sinalizar para desestabilização deste modelo, abrindo espaços para a produção de conhecimentos pluriversitários (SANTOS, 2010).

Isto implica, ainda, indagarmos se a formulação da política de educação em gênero, no âmbito do Programa de Formação para Diversidade, do qual faz parte o GPP-GeR, consiste no atendimento de um contra-movimento subalterno capaz de forçar o desenvolvimento de uma ecologia de saberes, ou seja, "uma revolução epistemológica no seio da universidade22", resultante de "práticas que promovem uma nova convivência ativa de saberes ${ }^{23}$ " provenientes de indígenas, africanos, orientais, filósofos, religiosos, camponeses, populares, dentre outros (SANTOS, 2010, p. 75-77).

É possível dizer que a UFMA faz parte dessa dinâmica, legitimando determinados conhecimentos como científicos, produzindo discursos de "verdade", (FOUCAULT, 1988) e ampliando suas experiências de formação universitária, por

\footnotetext{
${ }^{20}$ KUHN, Thomas S. A estrutura das revoluções científicas. 5a ed. São Paulo: Editora Perspectiva, 1998.

21 MOTTA, Diomar das G. A questão de gênero na formação da educadora e do educador. Educação e Emancipação: revista do mestrado em educação. São Luís: UFMA, v.1, nº 2, jul./dez. 2002.

22 SANTOS, Boaventura de Sousa. A Universidade no Século XXI: para uma reforma democrática e emancipatória da Universidade. São Paulo, Cortez, 2010.

23 Ibdem, p. 77
} 
meio, dentre outras, das ações de extensão, atualização/aperfeiçoamento e especializações, as quais, muitas vezes são sustentadas por tentativas de teorização que permanecem presas em explicações causais e universais, sendo necessário seu exame crítico, expondo seus limites para que seja produzida uma abordagem alternativa (SCOTT, 1995), cujos conhecimentos nos ajudam na compreensão dos problemas das diferenciações das relações de gênero.

É a partir dessa lógica que, colocamos os estudos de gênero em questão nas tramas do curso GPP-GeR, problematizando, também, a importância do próprio espaço universitário na produção e circulação desses discursos, por meio de seus dispositivos organizacionais (licenciaturas, especializações, grupos de pesquisa, etc.). Para tanto, questionamos a concepção de gênero estudada neste curso com o desejo de garimpar ou indicar os debates que estejam endereçados a construções de gênero mais críticas e problematizadoras, pois, afastando-se dos pensamentos substancialista, resultantes das tradições clássicas de primazia tanto metafísica, empirista e racionalista, é possível, conforme Louro (2000, p. 20) "romper com as relações hierárquicas das salas de aula tradicionais, com o monopólio dos experts, bem como a dicotomia entre o objetivo e o subjetivo, a razão e a emoção ${ }^{24}$."

Os estudos, sobre a noção de gênero no curso GPP-GeR, aconteceram na modalidade de educação a distância que, atualmente, utiliza a convergência das tecnologias da informação e comunicação, idealizando um espaço de virtualidade para o processo de ensino e aprendizagem (MACHADO; BOAKARI, 2012), em que a distância não é apenas um aspecto geográfico, mas pedagógico (MOORE, KEARSLEY, 2010).

A EaD é também, formada por um conjunto de teorias, através das quais "os sistemas de ensino e aprendizagem são transformados e reorganizados para suprir as necessidades instrucionais e de conhecimento da sociedade $25 \%$. (ABOUD, 2008, p.18). Então, a partir de quais campos científicos e contextos, estes conhecimentos são produzidos na modalidade de educação à distância? Que epistemologias são utilizadas?

\footnotetext{
${ }^{24}$ LOURO, Guacira L. Currículo, Gênero e Sexualidade. Porto: Porto Editora, 2000.

25 ABOUD, Amanda F. Fundamentos da Educação a Distância: a teoria por trás do sucesso. In: SERRA, Antonio R. C.; SILVA, João A. R. (Orgs.). Por uma educação sem distância: recotes da realidade brasileira. São Luís: EDUEMA, 2008.
} 
Esses estudos foram desenvolvidos com seis turmas distribuídas nos municípios de: Caxias, Codó, Grajaú, Humberto de Campos, Imperatriz e Santa Inês do estado do Maranhão, as quais tiveram um total de 70 (setenta) cursistas que concluíram o curso. Desse universo, selecionamos o Pólo de Humberto de Campos, já que é o pólo que mais oferece possibilidades para, posteriormente, contatar os/as cursistas autores/as dos discursos selecionados para análise. Também, focalizamos, especialmente, o Módulo 2: Políticas Públicas e Gênero ${ }^{26}$ do curso porque trata das questões de gênero, objeto deste estudo. Este módulo está organizado com quatro unidades de estudo:

a) Unidade 1 - Gênero, Sexo e Sexualidade (15 horas): objetivou demonstrar as categorias de sexo, gênero e sexualidade, bem como as diferenças, apresentando a relevância destas para a elaboração e desenvolvimento de políticas públicas e suas formas de incorporação à ação cotidiana

b) Unidade 2 - Gênero e Hierarquia Social (10 horas): objetivou possibilitar um olhar aprofundado das relações e das hierarquias sociais com base no gênero, suas características fundamentais em diversos espaços, as formas como as diferenças são criadas e naturalizadas e seus impactos sobre a sociedade.

c) Unidade 3 - Desigualdades de Gênero no Brasil (20 horas): objetivou conhecer a partir da perspectiva de gênero os indicadores de desigualdades: educação, trabalho, saúde, pobreza/renda, violência/segurança.

d) Unidade 4 - Movimentos de mulheres (15 horas): objetivou mostrar as trajetórias das lutas empreendidas pelos movimentos feministas e outros movimentos sociais em especial o movimento de mulheres.

Neste estudo, utilizamos a unidade 1 porque constitui a fase inicial de discussão da categoria gênero no curso. Desse modo, utilizamos alguns discursos situados no contexto interpretativo do fórum de discussão, ferramenta usada para o desenvolvimento da seguinte atividade: "A partir do que estudou e refletiu na unidade 1 do módulo 2, compartilhe conosco o que compreendeu sobre as categorias Gênero, Sexo e sexualidade. Você também poderá comentar as postagens de suas/seus colegas”.

\footnotetext{
26 Informações disponíveis no ambiente do curso e organizadas pela professora-formadora do módulo, Zeila Albuquerque (http://www.avapg.ufma.br/)
} 
Com este fórum, analisamos alguns usos da noção de gênero no processo formativo do GPP-GeR, a partir das postagens de participantes deste curso, cujos sujeitos optamos por não identificá-los, embora tenham autorizado sua participação na pesquisa. Vejamos alguns desses discursos coletados do ambiente de aprendizagem $M_{o o d l e}{ }^{27}$ do GPP-GeR e partilhados entre 4 participantes neste fórum!

Discurso 1: O gênero [...] é uma ferramenta analítica que teoriza a questão da diferença sexual dando ênfase ao caráter fundamentalmente social das distinções baseadas no sexo, afastando o fantasma da naturalização e dando relevo ao aspecto relacional entre mulheres e homens, o que é essencial para descobrir a amplitude dos papéis sexuais e do simbolismo sexual nas várias sociedades e épocas. Acresce-se à significação uma articulação do gênero com classe e com raçaletnia, tendo em vista que as desigualdades de poder se organizam, no mínimo, conforme esses três eixos. (CURSISTA 1, grifo nosso)

Discurso 2: Sexo diz respeito às características físicas e anatômicas, enquanto Gênero está relacionado a uma construção social. Gênero está relacionado ao modo com que sociedade constrói os conceitos dos comportamentos esperados de homens e mulheres, comportamentos diferentes, que produzem e reforçam as relações de poder. Desse modo, o sexo, a natureza e o biológico, por si só, não determinarão quem seremos. Seremos aquilo que aprendemos desde o nosso nascimento, numa constante incorporação e internalização de valores e comportamentos esperados de nós, enquanto meninos ou meninas, rapazes e moças, homens e mulheres. (CURSISTA 2, grifo nosso)

Discurso 3: $O$ sexo biológico também não determina a sexualidade, ao contrário do que defende a corrente do essencialismo. A sexualidade é uma construção, um aprendizado, que se dá pela incorporação da nossa identidade de gênero e orientação sexual ao longo do tempo, uma posição que é defendida pelo construtivismo social. A sexualidade está intimamente relacionada com o gênero que, por sua vez, tem relação estreita com os movimentos feminista e LGBT... Sexualidade e gênero, portanto, não nascem com os indivíduos nem são imutáveis. Por se tratarem de objeto de construção social e cultural, espelham um momento da vida da pessoa e, por isso, são passíveis de mudança... (CURSISTA 3, grifo nosso)

Discurso 4: As teorias que utilizam o conceito de gênero são plurais, não existindo mesmo uma voz uníssona. Penso, entretanto, que o conceito da Raquel Soihet tem limitações cujo comentário pode ser interessante de ser feito. Este conceito, apesar de mencionar "o caráter fundamentalmente social das distinções baseadas no sexo", não aponta para uma desnaturalização da própria categoria SEXO a qual permanece como sendo do campo da natureza, havendo uma inscrição cultural sobre um corpo natural. Dessa forma, subsistiria a dicotomia NATUREZA X CULTURA. Fora isso, da forma como aparece o conceito, percebemos que a dicotomia HOMENS e MULHERES permanece, oposição que justamente contribui para a formatação da sociedade dentro dos parâmetros heterossexistas. Essas foram minhas impressões que gostaria de compartilhar com vocês. (CURSISTA 4, grifo nosso)

Discurso 5: Quando dizes que "Sexo diz respeito às características físicas e anatômicas, enquanto Gênero está relacionado a uma construção social" penso que cabe o mesmo comentário que fiz para a [discurso 1] acerca da permanência da dicotomia NATUREZA X CULTURA.

${ }^{27} \underline{\mathrm{http}: / / \text { www.avapg.ufma.br/mod/forum/view.php?id=11076 }}$ 
Dessa forma, permanecemos colocando o sexo no âmbito da natureza e dizendo que esse corpo sexuado é NEUTRO, deixando de lado todo o caráter político e do discurso biológico sem o qual não entenderíamos esse corpo como ele "é" aos nossos olhos. Não sei se me fiz entender, mas meu objetivo com esse comentário é problematizar a noção do corpo, do que tu chamas de "sexo biológico" como algo NATURAL. (CURSISTA 4, grifo nosso)

Esses discursos podem ser interpretados em dois blocos:

No primeiro bloco discursivo: os discursos 1, 2 e 3 apresenta a categoria gênero como categoria analítica da diferença sexual, propondo questionar a normatividade das desigualdades que se traduzem em relações de poder. É uma discussão que leva a problematizar a própria noção de gênero como categoria analítica, já que, nesse discurso, o gênero se mantém preso na matriz heterossexual.

Mostra, também, um problema com a definição e classificação dos conceitos. No discurso 2, mais nitidamente, a noção de sexo aparece como problema conceitual, é essencialista e não deveria interferir na sexualidade e no gênero. $O$ gênero é a alternativa que mobiliza a ideia de conteúdo cultural, de construção social. A proposta seria pensar sobre a noção de gênero em seu "caráter construído, histórico, particular e localizado28" (LOURO, 2000, p. 95).

Os discursos de gênero, presentes em qualquer processo formativo (família, escola, igreja, associações, partidos políticos, movimentos sociais, dentre outros), podem influenciar as relações sociais cotidianas como "as representações encontradas nos livros didáticos ou nos jornais, revistas e filmes consumidos pelas/os estudantes; produzindo novos textos, não-sexistas e não-racistas ${ }^{29 "}$ (LOURO, 2004, p. 124). São, portanto, fundados politicamente e epistemologicamente, sustentando ou desconstruindo práticas de natureza imutáveis.

Porém, a ideia de que gênero é uma construção social soa como algo natural e recorrente, nesses discursos. Será que não mostra o seu caráter constitutivo? Não mostra as implicações dessa construção nos processos de relações de poder, de exclusão e dominação sociocultural? A construção nesses discursos é imutável? "Seremos aquilo que aprendemos desde o nosso nascimento", não tem outro jeito? Talvez, seja necessário admitir que, conforme Louro (2000, p. 39):

\footnotetext{
${ }^{28}$ Ibdem, p. 95.

${ }^{29}$ Ibdem, p. 124.
} 
a própria Natureza é, também, uma construção histórica e social. A nossa forma de 'chegar' à Natureza, de nos referirmos ao que é, ou não é, natural também se dá pela linguagem, também se faz por meio de símbolos e de representações e também se modifica historicamente ${ }^{30}$.

Mas, como o uso da categoria gênero poderia desconstruir a noção de sexo natural? Foi para se referir a um conjunto de elementos socioculturais que são atribuídos aos corpos, definindo o que seja masculino e feminino que, inicialmente, a noção de gênero foi empregada, buscando, afastar-se das determinações biológicas a que se refere o sexo anatômico.

Para Saffioti (1999, p. 160) na obra de Simone de Beauvoir, "O Segundo Sexo", publicada em 1949, que traz sua célebre frase: "Ninguém nasce mulher, torna-se mulher" está "a manifestação primeira do conceito de gênero. Ou seja, é preciso aprender a ser mulher, uma vez que o feminino não é dado pela biologia, ou mais simplesmente pela anatomia, e sim construído pela sociedade ${ }^{31}$ ". Carvalho (2011), também assegura que o conceito foi consolidado nos anos 1950/1960 na tradição teórica funcionalista e essencializante da percepção de Simone de Beauvoir.

Mas, é nos anos 1980 que amplia-se o debate crítico acerca dessa visão funcionalista, afastando, sobremaneira, as noções de gênero das construções de base natural fixa para acentuar, por meio da linguagem, o caráter relacional, plural e "fundamentalmente social das distinções baseadas no sexo ${ }^{32 "}$ (SCOTT, 1995, p. 72) e que são constituintes da identidade dos sujeitos.

Nesse sentido, podemos afirmar ainda, segundo Carvalho (2011), que os estudos de Joan Scott são os mais citados no Brasil. O artigo "Gênero, uma categoria útil de análise histórica”, foi publicado, originalmente, em 1986 e, posteriormente, incluído como capítulo no livro Gender and the politics of History, de 1988, sendo traduzido por Guacira Lopes Louro, em 1990, ganhando grande repercussão no campo de estudos de

\footnotetext{
30 Ibdem, p. 39.

31 Ibdem, p. 160.

32 SCOTT, Joan Wallach. Gênero: uma categoria útil de análise histórica. Educação e Realidade. Porto Alegre, v. 20, n. 2, p. 71-99, jul./dez. 1995.
} 
gênero no país, discutindo formas de construcionismo social, na tentativa de superação do período que enfatizou a biologia como destino.

Scott (1995, p. 75) trata do uso da noção de gênero de modo relacional, rejeitando posturas que enfatizam estudos sobre mulheres de maneira isolada, perpetuando a ideia de que a experiência de um sexo não tem nada a ver com o outro sexo. O termo gênero "torna-se uma forma de indicar 'construções culturais' - a criação inteiramente social de ideias sobre os papéis adequados aos homens e mulheres. 'Gênero' é, segundo esta definição, uma categoria social imposta sobre um corpo sexuado 33 ". Isto porque, o gênero é utilizado como capaz de constituir relações sociais que são fundadas, a partir das diferenças que são percebidos entre os sexos, dando significado as relações de poder, invocando outros eixos como: classe e raça para análise das desigualdades de poder.

Nessa direção, Lauretis (1994) argumenta que o gênero não representa um indivíduo, mas uma relação social, ou seja, o indivíduo é representado por meio de uma classe, mas também pela raça, etnia, já que não é um ser unificado, mas múltiplo e contraditório, também, assim como a sexualidade não é propriedade dos corpos nem algo que existe a priori. Nesse caso, Lauretis (1994) propõe pensar o gênero como uma representação e uma auto-representação, apontando formas ambíguas de entender que o gênero é construído por diferentes tecnologias sociais, ao mesmo tempo em que, participa de sua própria construção atribuindo significados aos indivíduos.

Além desses estudos podemos aprofundar ou problematizar mais ainda as diferenças entre os sexos, por meio dos argumentos de Butler (2012, p. 25) ao colocar em suspenso a ideia de que sexo tenha, mesmo, um caráter imutável e que possa existir alguma distinção entre sexo e gênero. A autora aponta que "sexo seja tão culturalmente construído quanto o gênero. [...] o gênero não está para a cultura como o sexo para a natureza.

É o que aponta o segundo bloco discursivo: os discursos 4 e 5 recusa a dicotomia gênero e sexo e rejeita a noção de gênero como interpretação cultural do sexo, problematizando-o, também, como construção, tal como aprendemos com Beauvoir (1980, p. 9): "Ninguém nasce mulher: torna-se mulher. Nenhum destino

33 Ibdem, p. 75. 
biológico, psíquico, econômico define a forma que a fêmea humana assume no seio da sociedade $34 "$

Nesse caso, para Butler (2012), a cultura é que passa a ser o destino, além de que Beauvoir continua mantendo o dualismo entre mente e corpo. Essa visão ainda sobressai-se porque o gênero, como categoria analítica, é construído nos "limites de uma experiência discursivamente condicionada ${ }^{35 "}$ (BUTLER, 2012, p. 28) por um discurso cultural hegemônico. Ora, é possível produzir um discurso sem um contexto? O contexto não faz parte do discurso?

A preocupação que emerge dessa discussão não se trata de defender ou rejeitar a noção do construcionismo social, mas, sobretudo, queremos chamar atenção para a maneira como os gêneros aparecem nos discursos porque sem significado não há experiência (Scott, 1999). Nesses discursos, os/as cursistas posicionaram-se, por meio da linguagem que, por sua vez, constitui, a interpretação da noção de gênero que, por outro lado, ainda precisa ser interpretada. A interação que se dá neste processo tem condições de "empreender uma crítica radical que busque libertar a teoria feminista da necessidade de construir uma base única e permanente36" (BUTLER, 2012, p. 23).

Logo, permeia no espaço formativo do GPP-GeR, de um lado, um movimento assimilacionista das leituras de gênero como construção sociocultural e sexo como características física e anatômica, de outro, um movimento problematizador que aponta as noções de gênero, sexo e sexualidade como construção cultural. A problematização ocorre pela interação, pelas experiências diversas, pela linguagem comunicacional entre saberes plurais, dentre outros. Nesse diálogo, há o reconhecimento da incompletude da noção de gênero e o desejo de insatisfação, de busca, de avançar, expondo os limites reguladores da linguagem hegemônica.

\section{Algumas Considerações...}

\footnotetext{
${ }^{34}$ BEAUVOIR, Simone. O Segundo Sexo: a experiência vivida. Trad. Sérgio Milliet. Rio de Janeiro: Nova Fronteira, 1980.

35 BUTLER, Judith. Problemas de gênero: feminismo e subversão da identidade. $4^{\mathrm{a}}$ ed. Rio de Janeiro, Civilização Brasileira, 2012.

${ }^{36}$ Ibdem, p. 23
} 
Os significados de gênero podem ser construídos a partir de diversos sistemas de pensamento: essencialistas, racionalistas, positivistas, dialético... Isto revela o quanto estamos envolvidos por um pensamento complexo que se cria e recria, historicamente, reconhecendo os limites epistemológicos introduzidos pela ciência, pois a "certeza generalizada é um mito ${ }^{37}$. (MORIN, 2007, p. 52-53).

Vimos que problematizar a noção de gênero é questionar a validade da epistemologia geral, hegemônica, principalmente aquela pautada na ideia de substância, reconhecendo obstáculos no seu uso. Este pensamento aparece, principalmente, no primeiro bloco de discurso, colocando relações de gênero para designar os sexos, naturalmente, construídos, conformando, de um lado, uma matriz inteligível (legitimada e hegemônica) e, de outro, uma matriz subversiva (subalterna).

Analisar os argumentos debatidos nos fóruns sobre a noção de gênero ajuda a reconhecer os movimentos complexos das lutas, crises e possíveis mudanças epistemológicas que produzem efeitos nas formas de pensar e agir nas relações sociais. Cada argumento, tomado como discurso constitui uma trama simbólica de desestabilização, desconstrução e reconstrução, que atribui significados aos sujeitos no mundo social.

Por tudo isso, a trama desses discursos consiste em um jogo estratégico de ação e reação; pergunta e resposta; dominação e esquiva; luta e outros, tende a produzir o que ele designa, já que possui uma força citacional para engendrar efeitos materializadores na construção dos sujeitos. São questões culturais europeias e não europeias em tensão, de um lado, permanece a luta pela manutenção do status quo, de outro tentativas de abalar o pensamento hegemônico substancialista, visando afirmação de diferentes conhecimentos, posições socioculturais.

Somente olhando estes discursos como práticas sociais fundadas e refundadas no decorrer da história (FOUCAULT, 1996) é que foi possível interpretar o sentido da noção de gênero nos discursos de alguns participantes (tutores/as e cursistas), do curso GPP-GeR e entender de que modo estão agindo e construindo a sua realidade social, considerando que, também, são produtos desse pensamento substancialista, de uma

${ }^{37}$ Ibdem, p. 52-53 
cosmovisão mais ocidental. Isto não seria possível se tomarmos os discursos distantes de seu contexto de produção, contudo, continuamos indagando: será que são discursos já internalizados por seus sujeitos? Ou, fazem parte do conjunto de leituras realizadas no curso? Será que são reproduções de ideias e noções somente para fins do curso? Ou, há possibilidades que se convertam em experiências cotidianas, em formulação de políticas públicas de gênero?

De qualquer modo, os discursos de gênero, aqui analisados, são bastante complexos e carregados de significados ideológicos que, ao mesmo tempo, podem ser interpretados e materializar práticas sexistas e discriminatórias, mas também, ao interrogarem criticamente as relações de gênero na sociedade, reconhecendo suas armadilhas e seu poder inscrito por meio do poder das práticas colonialistas poderá materializar novas formas de pensar e agir.

Logo, a relevância problematizadora, deste espaço formativo analisado no GPPGeR, precisa ser valorizada, pois, nos coloca diante de múltiplas contestações e indeterminações que Butler (2012) preferiu chamar de "problemas de gênero"!

\section{Referências}

ABOUD, Amanda F. Fundamentos da Educação a Distância: a teoria por trás do sucesso. In: SERRA, Antonio R. C.; SILVA, João A. R. (Orgs.). Por uma educação sem distância: recotes da realidade brasileira. São Luís: EDUEMA, 2008. p. 15-29.

ANDRÉ, Marli E. D. A. A produção acadêmica sobre formação de professores: um estudo comparativo das dissertações e teses defendidas nos anos 1990 e 2000. Formação Docente - Revista Brasileira de Pesquisa sobre Formação Docente, Belo Horizonte, v. 1, n. 1, ago./dez. 2009. P. 41-56. Disponível em: < $\underline{\mathrm{http}: / /}$ formacaodocente.autenticaeditora.com.br. $>$. Acesso em: 12 jun. 2013.

- Formação de professores: a constituição de um campo de estudos. Educação, Porto Alegre, v. 33, n. 3, p. 174-181, set./dez. 2010. Disponível em: $<$ http:// revistaseletronicas.pucrs.br/ojs/index.php/faced/article/view/8075/5719>. Acesso em: 12 jun. 2013.

BACHELARD, Gaston. A formação do espírito científico: contribuições para uma psicanálise do conhecimento. Rio de Janeiro: Contraponto, 1996. 
BEAUVOIR, Simone. O Segundo Sexo: a experiência vivida. Trad. Sérgio Milliet. Rio de Janeiro: Nova Fronteira, 1980.

BOAKARI, Francis Musa. Mulheres afrodescendentes de sucesso: confrontando as discriminações brasileiras. In: SEMINÁRIO INTERNACIONAL FAZENDO GÊNERO, 9., 2010, Florianópolis. Anais eletrônicos do Fazendo Gênero 9. Florianópolis: UFSC, 2010. Disponível em: $<\underline{\text { http://www.fazendogenero.ufsc.br/9/ }}$ resources/anais/1278155240 ARQUIVO_FAZENDGENERO9-2010BOAKARI.TEXTO.pdf.>. Acesso em: 17 set. 2012.

BOURDIEU, Pierre. Linguagem e poder simbólico. In: A economia das trocas lingüísticas: o que falar quer dizer. São Paulo: EDUSP, 1996. p. 81-128.

BRAGA, Adriana. Etnografia segundo Christine Hine: abordagem naturalista para ambientes digitais. In: Revista da Associação Nacional dos Programas de PósGraduação em Comunicação (E-compós). Brasília, v.15, n.3, set./dez. 2012. Disponível em: http://www.compos.org.br/seer/index.php/e-compos/article/viewFile/856/638. Acesso em: 20 janeiro 2014.

BRASIL. Ministério da Educação. Manual da Rede de Educação para a Diversidade. Disponível em: < http://portal.mec.gov.br/index.php? option=com_content\&view=article\&id=12322\&Itemid=561. $>$. Acesso em: 2 mar. 2012.

BUTLER, Judith. Problemas de gênero: feminismo e subversão da identidade. $4^{\mathrm{a}}$ ed. Rio de Janeiro, Civilização Brasileira, 2012.

CARVALHO, Marília Pinto de. O conceito de gênero: uma leitura com base nos trabalhos do GT Sociologia da Educação da ANPEd (1999-2009). Revista Brasileira de Educação v. 16 n. 46, p. 99-117, jan./abr. 2011.

CASTELlS, Manuel. A Sociedade em Rede. São Paulo: Paz e Terra, 2011, v. 1.

CENSO EAD.BR: relatório analítico da aprendizagem a distância no Brasil 2013. Trad. Maria Thereza Moss de Abreu. Curitiba: Ibpex, 2014.

DIAS, Rosilânia A.; LEITE, Lígia S. Educação a Distância: da legislação ao pedagógico, Petrópolis, RJ: Vozes, 2010. 
FOUCAULT, Michel. A verdade e as formas jurídicas. Rio de Janeiro: Nau Ed., 1996.

Edições Graal, 1988.

História da Sexualidade I: a vontade de saber. Rio de Janeiro:

HEILBORN, Maria Luiza; ARAÚJO, Leila; BARRETO, Andreia. (Org.). Gestão de Política Públicas em Gênero e Raça | GPP-GeR: módulo II. Rio de Janeiro: CEPESC; Brasília: SPM/MEC, 2010.

- Gestão de Política Públicas em Gênero e Raça|GPP-GeR: módulo

I. Rio de Janeiro: CEPESC; Brasília: SPM/MEC, 2010a.

HENRIQUES, Ricardo et al. Gênero e Diversidade Sexual na Escola: reconhecer diferenças e superar preconceitos. Brasília: SECAD/MEC, 2007.

INTERATIVA. Revista do Núcleo de Educação a Distância da Universidade Federal do Maranhão. Edição n ${ }^{\circ}$ 1, ano 1, dez. 2008.

Revista do Núcleo de Educação a Distância da Universidade Federal do Maranhão. Edição n ${ }^{\circ}$ 2, ano3, jan. 2010.

KUHN, Thomas S. A estrutura das revoluções científicas. $5^{\mathrm{a}}$ ed. São Paulo: Editora Perspectiva, 1998.

LAURETIS, Teresa de. A tecnologia do gênero. In: HOLLANDA, Heloisa B. de. Tendências e impasses: o feminismo como crítica da cultura. Rio de Janeiro: Rocco, 1994. p. 206-242.

LOURO, Guacira L. Currículo, Gênero e Sexualidade. Porto: Porto Editora, 2000.

. Gênero, sexualidade e educação: uma perspectiva pós-estruturalista.

Petrópolis: Vozes, 2004.

MACHADO, Raimunda N. da Silva. Mulher negra: ressignificando o discurso no espaço escolar. Dissertação (Mestrado em Ciências Sociais). Programa de Pós Graduação em Ciências Sociais/ Universidade Federal do Maranhão. São Luís: UFMA, 2008. 
MACHADO, Raimunda N. da S., BOAKARI, Francis M. Educação a distância das "emergências"? In: VII Encontro de pesquisa em educação da UFPI. Teresina: EDUFPI, 2012, p. 1023-1031.

MOORE, Michael G.; KEARSLEY, Greg. Educação a distância: uma visão integrada. São Paulo: Cengage Learning, 2010.

MORIN, Edgar [et all]. Educar na era planetária: o pensamento complexo como método de aprendizagem no erro e na incerteza humana. São Paulo: Cortez, Brasília, DF: UNESCO, 2007.

MOTTA, Diomar das G. A questão de gênero na formação da educadora e do educador. Educação e Emancipação: revista do mestrado em educação. São Luís: UFMA, v.1, n ${ }^{0}$ 2, jul./dez. 2002.

SAFFIOTI, Heleieth I. B. O poder do macho. São Paulo: Moderna, 1987.

. Primórdios do conceito de gênero. Cadernos pagu, n. 12, p.157-163, 1999 ;

SANTOS, Boaventura de Sousa. A Universidade no Século XXI: para uma reforma democrática e emancipatória da Universidade. São Paulo, Cortez, 2010.

SANTOS, Boaventura de Sousa. Um discurso sobre as ciências. $5^{\text {a }}$ ed. São Paulo: Cortez, 2008.

SCOTT, Joan Wallach. Gênero: uma categoria útil de análise histórica. Educação e Realidade. Porto Alegre, v. 20, n. 2, p. 71-99, jul./dez. 1995.

. Experiência. In: LEITE DA SILVA, Alcione et al (Orgs.). Falas de gênero: teorias, análises, leituras. Florianópolis: Editora Mulheres, 1999. p. 21-55. 